ReVISTA INTERnaCional de Sociología (RIS)

Vol.68, № 3, Septiembre-DicIemBre, 555-575, 2010

ISSN: 0034-9712

elSSN: 1988-429X

DOI:10.3989/ris.2007.11.04

\title{
LA VIRTUD CÍVICA COMO CONCEPTO SOCIOLÓGICO Definición y extensión social
}

\author{
CIVIC VIRTUE AS A SOCIOLOGICAL CONCEPT \\ Definition and Social Extension
}

\author{
JORDI TENA \\ Universitat Autònoma de Barcelona. España \\ Jordi.Tena@uab.cat
}

\begin{abstract}
Resumen
En este trabajo se intenta ofrecer algunas líneas básicas de lo que debería ser una definición sociológica del concepto de virtud cívica. Se sostiene que debemos entender la virtud cívica como la motivación para actuar de forma públicamente orientada. Se argumenta que la virtud cívica es constituida por las motivaciones que causan las acciones concretas, no por las conductas ni por las disposiciones de carácter. Asimismo, también se sostiene que las motivaciones virtuosas pueden consistir en motivaciones para la cooperación y para sancionar a los que no cooperen, así como en motivaciones de tipo solidario y altruista. No obstante, se sostiene también que no todas las motivaciones morales y, en particular, no todas las motivaciones altruistas pueden ser calificadas de virtuosas. Finalmente, se argumenta que la extensión social de la virtud cívica debe consistir en la extensión de un cuerpo de normas morales y sociales públicamente orientadas. En este sentido, se aportan razones en favor de concebir la correcta articulación entre virtud cívica y diseño institucional como un óptimo social.
\end{abstract}

\section{Palabras Clave}

Altruismo, Cooperación, Egoísmo, Motivación, Normas morales y sociales, Solidaridad.

\begin{abstract}
This paper attempts to offer a number of basic lines for what endeavours to be a sociological definition of civic virtue. Civic virtue is defined as a motivation for public-spirited action. The paper argues that civic virtue is constituted by motivations, which cause specific actions, not by behaviours or character dispositions. In the same way, it is also claimed that virtuous motivations can consist either on motivations to cooperate and to punish free-riders or on supportive and altruistic ones. However, it is remarked that moral motivations and, particularly, altruistic motivations, are not always virtuous. Finally, the social extension of civic virtue consists in the emergence of a publicly spirited body of moral and social norms. This fact, and others that we will see throughout the paper, offer reasons in favour of conceiving the correct articulation between civic virtue and institutional design as a social optimum.
\end{abstract}

\section{KEYWORDS}

Altruism, Cooperation, Moral and Social Norms, Motivation, Selfishness, Solidarity. 


\section{INTRODUCCIÓN ${ }^{1}$}

El concepto de "virtud cívica" es uno de los más recurrentes de la Historia de la Filosofía y de las Ciencias Sociales. Llama la atención sin embargo que, siendo esto así, exista poco acuerdo acerca de qué debemos entender exactamente con dicho término y pocos intentos de definición y operativización sistemáticas del mismo. La constatación de esta realidad no debe entenderse como una recriminación hacia los autores que se han referido al mismo a lo largo de la historia, desde Aristóteles hasta Philip Pettit pasando por Cicerón, Maquiavelo o Tocqueville por citar tan sólo algunos de los nombres más destacados. Los autores pueden entrar más o menos en detalle en la definición y la operativización de un concepto según convenga a sus fines. No obstante, la ausencia de acuerdo unánime en torno a una definición precisa supone una limitación para la Sociología y la Ciencia Política modernas, de modo particular en lo que se refiere a la investigación de mecanismos de diseño institucional que tengan por finalidad el refuerzo y la creación de virtud cívica.

El presente trabajo trata de ofrecer una definición sociológica de lo que podemos entender por virtud cívica. No se pretende en estas páginas dejar cerrada la discusión ni ofrecer las respuestas definitivas a la misma. La finalidad es mucho más modesta. Se trata más bien de ofrecer algunos principios básicos que bien podrían constituir un punto de partida para una investigación analíticamente rigurosa que trate de desvanecer algunas confusiones habituales sobre el tema.

En lo que sigue se sostendrá que la virtud debe ser entendida como la motivación para la acción públicamente orientada. Una tesis secundaria rezará que la extensión social de la virtud consistirá en la promoción de un cuerpo de normas morales y sociales públicamente orientadas.

En primer lugar, se efectuará un breve repaso de los distintos usos del concepto de virtud cívica a lo largo de la historia del pensamiento occidental. Dicho repaso permitirá identificar algunos lugares comunes acerca de lo que debemos entender por virtud cívica. Sería necesario empero abordar de forma sistemática dichos lugares comunes a fin de poder llegar a establecer un concepto mínimamente operativo.

En segundo lugar, se discutirán algunos aspectos concretos de lo que constituye la virtud cívica. Se empezará por abordar algunas de las implicaciones que resultan de concebir la virtud cívica como un tipo de motivación, en particular se sostendrá que la virtud no es ni un tipo de disposición ni de conducta. Posteriormente, tratará de explorarse qué tipo de motivaciones pueden ser públicamente orientadas. En este sentido, se sostendrá que la motivación virtuosa puede consistir en motivaciones para la cooperación

\footnotetext{
${ }^{1}$ El presente trabajo se ha beneficiado de los comentarios de José A. Noguera. Por otro lado, se ha beneficiado también de la concesión de dos proyectos de I+D+l: uno del Ministerio de Educación y el FEDER con referencia SEJ2006-0959/SOCI, y otro del Ministerio de Ciencia e Innovación con referencia CSO2009-09890.
} 
y para sancionar a los que no cooperen, así como en motivaciones de tipo solidario y altruista. No obstante, como tendrá oportunidad de verse, no todas las motivaciones morales y, en particular, no todas las motivaciones altruistas pueden ser calificadas de virtuosas.

Finalmente, se argumentará que una comunidad en la que la virtud cívica se halla socialmente extendida es aquélla en la que existe un cuerpo de normas morales y sociales públicamente orientado que guía generalmente la conducta de los individuos. Concebir de este modo la extensión social de la virtud cívica permite reconocer que pueden existir situaciones en las que, aun existiendo la virtud cívica, los agentes no actúan de forma correcta. Este hecho, junto con otros que irán apareciendo a lo largo del trabajo, aporta razones a favor de concebir la correcta articulación entre virtud cívica y diseño institucional como un óptimo social. La caracterización defendida en estas páginas supone que la virtud cívica es transversal a dos debates históricamente recurrentes. La virtud puede adoptar la forma de motivaciones condicionales o incondicionales, así como consecuencialistas o no consecuencialistas.

\section{LA VIRTUd CÍVICA EN ALGUNOS CLÁSICOS DEL PENSAMIENTO OCCIDENTAL}

La "virtud cívica" se erigió como uno de los conceptos centrales de la filosofía griega clásica. La virtud es entendida siempre, en el seno de dicha tradición, como capacidad psicológica para gobernar autónomamente la propia existencia social (Bertomeu y Domènech, 2005). Pero esa capacidad no puede limitarse al logro de la autonomía de carácter necesaria para autogobernarse en la vida privada (con sólo eso se podría seguir siendo un idiotés, un "idiota moral", es decir, alguien que sólo mira por y para su casa). La virtud comprende también una vocación más o menos intensa por los asuntos públicos, y eso es lo que hace de un individuo libre un polités, un "ciudadano".

Dentro de la tradición clásica fue Aristóteles (1981) el que quizá con mayor dedicación y acierto se dedicó a tratar de ofrecer una definición relativamente sistemática del concepto. En la Ética a Nicomaco adopta una concepción disposicional del mismo. Para que un acto sea virtuoso debe reunir algunas condiciones entre las que se incluye su motivación, pero debe también proceder de un carácter firme e invariable, si no es así, puede ser un acto que realizaría una persona virtuosa pero no será en sí mismo un acto virtuoso (Hurka 2006).

La virtud cívica también constituyó, como no podía ser de otra forma, una preocupación central para la filosofía del mundo romano antiguo. Entroncando directamente con la concepción griega, Cicerón $(1989,1992)$, probablemente el más reputado de los filósofos romanos, entendía la virtus como el conjunto de capacidades que cada hombre libre debe poseer en tanto que ciudadano, a saber, aquellas capacidades que le permiten servir al bien común por voluntad propia, y de este modo defender la libertad de la comunidad para, en consecuencia, asegurar el camino hacia la grandeza así como la propia libertad individual. De entre dichas capacidades sobresaldrían de modo especial 
el coraje para pelear contra los enemigos de la República y la prudencia y otras cualidades cívicas necesarias para desempeñar un papel activo y efectivo en la vida pública. Esta idea constituyó el fundamento de la virtú de los teóricos italianos posteriores y de la civic virtue o public spiritedness de los humanistas cívicos ingleses (Ovejero, Martí y Gargarella 2004). Para estos últimos, la virtud tenía una doble dimensión, por un lado requería de la capacidad para discernir lo que el bien público requiere y, por el otro, exigía la motivación para actuar según sus dictados (Brennan y Hamlin 1995). En este sentido, la virtud cívica comprendería lo que, en el lenguaje de las ciencias sociales modernas, podríamos denominar como una dimensión cognitiva y una motivacional².

Nos basta con este breve muestreo de las distintas caracterizaciones del concepto de virtud cívica a lo largo de la historia del pensamiento occidental para comprobar que existen toda una serie de lugares comunes compartidos acerca de lo que debe entenderse por virtud que se van repitiendo a lo largo del tiempo. No existen empero, tal y como se ha apuntado, demasiados intentos de tratamiento sistemático de dichos lugares comunes. En lo que sigue se tratarán de esbozar algunos de los aspectos que debería abordar un trabajo de esa naturaleza.

\section{¿MOTIVACIONES O DISPOSICIONES?}

Un debate recurrente acerca de la virtud se refiere al hecho de si lo que la constituye son las disposiciones motivacionales y los rasgos estables del carácter o las motivaciones concretas que encontramos tras una acción virtuosa específica ${ }^{3}$. Siguiendo a T. Hurka (2006) se optará por la segunda postura ${ }^{4}$. De este modo, nada impediría que considerásemos como virtuoso un acto de generosidad de un ciudadano que se comporta habitualmente de forma egoísta (siempre que se trate de generosidad genuina, claro está). Puede incluso que nos sorprenda agradablemente ese comportamiento inusualmente generoso y que lo alabemos por ello animándolo a trabajar su carácter y a continuar por ese camino. Del mismo modo, nada impide tampoco, desde esta perspectiva, que, sin negar su trayectoria ni su integridad moral, critiquemos un acto incorrecto puntual de una persona que alberga disposiciones correctas y que suele actuar de la forma adecuada pero que, en un momento dado, puede haber sucumbido, por ejemplo, a la debilidad de la voluntad.

\footnotetext{
2 También Putnam (2000) sostiene que es el "reconocimiento" y la "búsqueda" constantes del bien público lo que mejor caracteriza la virtud cívica.

${ }^{3}$ El término "disposición" se utiliza aquí en el sentido que suele dársele en ciencias sociales, prácticamente como sinónimo de rasgo estable de carácter. Se dirá que un individuo tiene una disposición para actuar de determinada manera en determinadas circunstancias de forma análoga a como, por ejemplo, podemos sostener que el azúcar alberga la disposición de disolverse en el agua también en determinadas circunstancias.

${ }^{4}$ Podría decirse que el punto de vista que aquí se adopta se centra en la acción y no en el agente.
} 
Desde este punto de vista, no se trata de que las disposiciones no sean importantes para la virtud, al contrario, son de una importancia fundamental. De lo que se trata es de que las disposiciones tienen un papel instrumental para la virtud. Damos mucha importancia a las disposiciones virtuosas pero se la damos porque y sólo porque las disposiciones virtuosas generalmente tenderán a generar motivaciones virtuosas mientras que las disposiciones viciosas tenderán a generar motivaciones viciosas, pero no siempre una motivación virtuosa sigue a una disposición virtuosa ni una motivación viciosa sigue a una disposición viciosa.

\section{¿MOTIVACIONES O CONDUCTAS?}

Otro debate muy relacionado con el anterior es el de si lo importante es la conducta o la motivación. Evidentemente, ser virtuoso no es simplemente actuar de forma correcta sino hacerlo además por los motivos correctos (Jonson 2003; Ovejero, Martí y Gargarella 2004). Está claro que si el único motivo por el que pagamos nuestros impuestos es para evitar la prisión, nuestra conducta será correcta, realizaremos nuestra contribución al bien común, pero no virtuosa, no nos encontraremos motivados para actuar en aras de dicho fin. Sin embargo, de forma análoga al caso anterior, lo que realmente importa aquí es la conducta, siendo la motivación un mero instrumento para la misma (Goodin 1992). En síntesis, la motivación es constitutiva de la virtud, pero la virtud no es constitutiva de la conducta correcta, sino sólo instrumental para la misma. La corrección de una acción es independiente de los motivos que la impulsen.

En segundo lugar, cuando se diseñan instituciones, el objetivo debe ser conseguir que la gente cumpla con sus deberes de ciudadanía independientemente de las razones por las que lo haga. Lo que debe preocuparnos, por ejemplo, es que los ciudadanos paguen los impuestos, resulta indiferente si lo hacen porque se encuentran motivados por el bien común o porque simplemente no quieren ir a la cárcel.

Nuevamente, no se trata de que las motivaciones no sean importantes, que lo son y mucho. La cuestión es que la motivación (la virtud) tiene un valor exclusivamente instrumental. Si nos preocupan las motivaciones virtuosas es debido a que generalmente éstas dan lugar a acciones correctas, mientras que las motivaciones viciosas suelen dar lugar a acciones incorrectas en cuanto los incentivos para defraudar son lo suficientemente altos o el riesgo de ser descubierto es lo suficientemente bajo ${ }^{5}$.

\footnotetext{
${ }^{5}$ Hay aquí una cuestión importante que se aparca por el momento pero que será abordada más adelante. Dicha cuestión tiene que ver con los casos en que las motivaciones morales (aunque no virtuosas) dan lugar a acciones incorrectas mientras que motivaciones viciosas dan lugar a acciones correctas.
} 


\section{VIRTUD, ALTRUISMO Y EGoísMO}

En la Introducción de este trabajo se ha sostenido que la virtud debe ser entendida como la motivación para la acción públicamente orientada. A lo largo de las secciones precedentes se han discutido algunas implicaciones de concebir la virtud cívica como un tipo de motivación. A continuación tratará de explorarse qué tipos de motivaciones pueden ser de tipo públicamente orientado.

Otro problema frecuente al referirse a la virtud es el del papel que juegan en ella las motivaciones altruistas y egoístas 0 , más bien, el altruismo y la persecución del propio interés. Veamos cómo se resuelve este tema desde dos concepciones clásicas de la virtud: la de Tocqueville y la de Kant. En la concepción de Tocqueville los ciudadanos persiguen lo que él denominaba el "interés personal bien entendido" (Tocqueville [1835] 1969). Los ciudadanos persiguen su propio interés pero son conscientes de que la mejor forma de perseguirlo no es dejándose llevar por la perspectiva cortoplacista de la racionalidad instrumental, sino cooperando en la persecución del bien común si los demás también lo hacen. Ser virtuoso en este sentido es ser perfectamente racional, a saber, estar dispuesto a colaborar en los dilemas sociales si los otros también lo hacen, aunque eso implique sacrificar una parte del interés propio a corto plazo. Se trataría, por usar los términos de la moderna teoría de juegos, de un caso de cooperación condicionada.

La segunda concepción clásica acerca de la virtud que quisiera traer aquí a colación es la de Kant. Ésta es ya una concepción estrictamente deontológica. Según Kant los individuos virtuosos deben anteponer el bien común a su interés privado independientemente de lo que hagan los demás, independientemente, por tanto, de la utilidad y de las consecuencias de su acción (Herreros 2002).

La noción de virtud que se trata de sostener aquí se apoya ampliamente sobre ambas concepciones. Se entenderá que la conducta virtuosa es aquélla que se encuentra motivada hacia la cooperación, perfectamente racional (aunque egoísta al fin y al cabo), pero que también alberga importantes dosis de altruismo y solidaridad.

Goodin (1992) sitúa en la base de la motivación para actuar moralmente en política estar dispuesto a cooperar si los demás también lo hacen, estar motivado para seguir lo que denomina como la golden rule. Goodin deriva este concepto de la célebre máxima kantiana según la cual debemos tratar a los demás tal y como desearíamos ser tratados por ellos. De modo general, no defraudaremos si no deseamos que los demás nos defrauden a nosotros. Tal vez desearíamos no colaborar y que todos los demás lo hiciesen pero asumimos que eso no es viable y colaboramos de buen grado. Goodin piensa que este principio es aplicable a la mayoría de las situaciones de interacción social y se basa en él para justificar el apoyo de los ciudadanos a las políticas redistributivas de los Estados de Bienestar o las garantías constitucionales de los derechos civiles y políticos. En el nivel más básico, la máxima kantiana de tratar a los demás como nos gustaría ser tratados por ellos se refiere a dar y recibir el mismo "bien". Seré respetuoso con los demás si deseo que ellos lo sean conmigo. El bien en este caso es el respeto. Para poder aplicar esta máxima a situaciones de intercambio es necesario aumentar 
un grado la complejidad. En un intercambio de mercado se intercambian bienes distintos, de otra manera el intercambio no tendría ningún sentido. En este caso, la golden rule requiere, como ya se ha apuntado, cumplir las reglas del intercambio. Cumpliré las reglas si pienso que los demás también lo harán. Pero, para poder justificar a partir de este principio las prestaciones del Estado de Bienestar aún es necesario aumentar otro grado la complejidad.

Como es bien sabido, el mercado produce lo que los economistas denominan "fallos del mercado". En el caso que nos ocupa, el mercado es incapaz de producir bienes públicos y es necesaria la intervención de un agente regulador externo. Por lo que hace referencia a los bienes públicos podemos aplicar la golden rule del modo anterior, colaboraré en la producción de un bien público (reciclaré las basuras, por ejemplo) si pienso que los demás también van a hacerlo. Éste sería el caso de determinadas prestaciones universales del Estado del Bienestar, pero no de la mayoría de ellas. Muchas de las prestaciones del Estado del Bienestar no son universales, sino que van dirigidas a grupos concretos, y otras, aunque sean universales, no son utilizadas por los grupos de renta media y alta. Goodin introduce aquí la cuestión de la incertidumbre. En un mundo como el nuestro, caracterizado por elevados niveles de incertidumbre, apoyaré esas medidas si soy perfectamente racional ya que existe la posibilidad a medio o largo plazo de que termine necesitándolas.

Esta predisposición a la colaboración no es más que la operativización de la persecución del interés personal bien entendido que hemos encontrado en Tocqueville. Nótese que consiste en motivaciones egoístas. De hecho, puede acabar transformando en egoístas a individuos originariamente altruistas. Yo puedo apoyar las ayudas estatales para los desfavorecidos por puro altruismo o solidaridad, pese a que yo pueda pensar que nunca las necesitaré. Sin embargo, si se promueve la golden rule de Goodin, puede que acabe apoyando esas medidas debido a que me vuelvo consciente de que si, por ejemplo, hubiese una crisis económica que afectase seriamente al sector en el que desarrollo mi actividad laboral, yo necesitaría esas ayudas y que, por tanto, si soy perfectamente racional, debo apoyarlas incluso ahora que no las necesito. Es decir, mi apoyo altruistamente motivado podría devenir egoístamente motivado.

La motivación para la cooperación es por tanto el primer componente de la virtud. Nótese que este componente demanda muy poco en términos de moralidad, de hecho, demanda más aversión al riesgo que moralidad. De todas formas, como mínimo es necesario algún tipo de sentido moral que nos permita identificar cuál es la acción correcta que los demás esperan de nosotros ${ }^{6}$.

Goodin sostiene que la motivación para la cooperación se encuentra entre las más importantes motivaciones humanas. La evidencia empírica parece darle la razón a este respecto, pero hay una segunda dimensión de este fenómeno a la que Goodin no hace referencia y que casa bien con nuestras intuiciones acerca de lo que constituye la virtud

\footnotetext{
${ }^{6}$ Nuevamente nos encontramos ante la dimensión cognitiva de la virtud cívica.
} 
cívica. Los seres humanos generalmente no sólo nos encontramos motivados para cumplir las normas de la cooperación social sino que lo estamos también para sancionar a los que no lo hacen. Samuel Bowles y Herbert Gintis denominan "reciprocidad fuerte" (strong reciprocity) a esta doble motivación para cooperar y para sancionar a los incumplidores. En palabras de los autores, por reciprocidad fuerte se entiende:

una propensión a cooperar y compartir con aquellos que tienen una predisposición similar y una voluntad de castigar a aquellos que violan la cooperación y otras normas sociales, aun cuando el hecho de compartir y el castigo conlleven costos personales (Bowles y Gintis 2001: 173).

Esta segunda dimensión (sancionadora) de la reciprocidad fuerte entronca perfectamente con la tradición, en particular con la noción republicana de "vigilancia virtuosa" mencionada anteriormente y que resulta intuitivamente plausible incluirla en la caracterización que se está tratando de elaborar aquí?.

En la reciprocidad fuerte, la disposición a cooperar es condicional, mientras que la predisposición a sancionar es altruista. Que la cooperación es condicional resulta bastante evidente: sólo se coopera con aquellos que también lo hacen. Pero sancionar es incondicional y altruista. Se sanciona en todos los casos percibidos de violación de la norma, generando de este modo un beneficio colectivo aunque al hacerlo se incurra en costes individuales y no existan expectativas de ganancia futura.

De lo anterior se desprende que la virtud cívica tanto puede adoptar la forma de una motivación incondicional como la de una condicional. Pero estar motivado para cooperar en los dilemas sociales y para sancionar a los transgresores, siendo muy importante, no resulta suficiente. La virtud puede requerir en algunas situaciones importantes de un grado más importante de moralidad, puede requerir de motivaciones genuinamente altruistas y/o solidarias.

Imaginemos el caso de un grupo desfavorecido perfectamente delimitado, por ejemplo, la población negra en los Estados Unidos del esclavismo o de la segregación. Si yo soy un ciudadano blanco perfectamente racional, en esa situación lo que haré será apoyar la explotación de los miembros de ese grupo. Imaginemos que soy el propietario de una plantación de algodón. Mi interés a corto, medio y largo plazo consistirá en la perpetuación del statu quo y, por muy mal que puedan llegar a irme las cosas, sé que nunca me volveré negro de modo que nunca me encontraré yo en esa situación. Obviamente, en estos casos, tal vez poco numerosos pero muy importantes, la virtud requiere ir más allá de la golden rule y la motivación para sancionar. Estos grupos se encuentran

\footnotetext{
${ }^{7}$ Se afirma que entronca con la noción de vigilancia virtuosa en el sentido de que los ciudadanos deben preocuparse de que sus conciudadanos y, de un modo muy especial, sus representantes (sus agentes) actúen correctamente. No obstante, en la tradición republicana, la vigilancia se refiere al diseño de instituciones de control y rendición de cuentas y no al cumplimiento de normas sociales.
} 
en una situación de dependencia estructural que hace que puedan ser explotados por los poderosos. Goodin hace referencia en este caso a otra célebre máxima kantiana que sostiene que quien está en una posición de poder tiene la obligación moral de no explotar y de proteger a los que se encuentran en una posición de debilidad. Goodin entiende por altruismo estar motivado, de forma más o menos imperfecta, por este principio. Del mismo modo que con la golden rule, Goodin identifica estas motivaciones altruistas en la naturaleza humana ${ }^{8}$. Conceptos como el de "piedad cristiana" que regía en las sociedades medievales o en la España franquista, o el conservadurismo compasivo en los EE.UU, podrían ser entendidos a la luz de esta idea. El señor feudal podía disponer de la vida y de la muerte de sus súbditos pero se esperaba de él que en la práctica se comportase de modo caritativo y evitase la crueldad innecesaria. Goodin se queda aquí en su demanda de moralidad política pese a que reconoce que el altruismo es un second best, siendo el first best la eliminación de las condiciones estructurales que hacen posible la dominación.

Dado que lo que aquí nos ocupa es la virtud cívica, resultaría profundamente contraintuitivo que nos detuviésemos en este punto y aceptásemos la caridad cristiana o el conservadurismo compasivo como el grado más elevado de las motivaciones virtuosas. Para poder ir más allá me apoyaré en los conceptos de "solidaridad" de Arnsperger y Varoufakis (2003) y de "altruismo perfecto" de Kolm (1983).

Según Arnsperger y Varoufakis la solidaridad se dirige hacia un grupo desfavorecido. Existen ciertas características que son producto de algún infortunio y que escapan A la responsabilidad del que las padece, por ejemplo, ser víctima de una catástrofe natural. Compartir esa característica nos permite identificar a un grupo; por ejemplo, podemos hablar de las víctimas del tsunami que asoló las costas del sureste asiático. Cuando somos solidarios empatizamos con los miembros del grupo desfavorecido. Esa empatía permite que dirijamos nuestra generosidad hacia los miembros de ese grupo de forma absolutamente desinteresada, sin necesidad de que exista un requerimiento moral explícito para que lo hagamos aunque, eso sí, argumentamos nuestra acción sobre la base de fuertes razones específicas de tipo moral.

Con el concepto de solidaridad logramos capturar la motivación para dar sin esperar nada a cambio, de forma puramente altruista. Esta idea no sólo debe entenderse como aplicable a lo que solemos considerar habitualmente como grupos desfavorecidos, sino a cualquier individuo o grupo que necesite nuestra ayuda en un momento dado, aunque no exista ni la más mínima posibilidad de que esa persona ni ninguna otra nos devuelva jamás el acto de altruismo. Un hombre puede ceder su asiento en el autobús a una mujer embarazada sin que se pueda decir, en el sentido habitual de la expresión, que las embarazadas conforman un grupo desfavorecido, sin que espere que haya una ocasión futura en la que ella le pueda devolver el favor y sin que exista la posibilidad de que él se

\footnotetext{
${ }^{8}$ Frölich y Oppenheimer (1992) han mostrado empíricamente la existencia de lo que ellos denominan la generosidad de las necesidades básicas.
} 
quede "embarazado" de modo que otros desconocidos le cedan el asiento en el autobús. El concepto de solidaridad, tal y como se plantea aquí, abarca las nociones de simpatía y compromiso de A. Sen (1986). Podemos solidarizarnos con un determinado grupo por simpatía, porque nos hace sufrir su sufrimiento por así decirlo. Tal y como argumenta el propio Sen, podemos movilizarnos contra la tortura porque el conocimiento de su existencia nos enferma. Para sostener esto no necesitamos apartarnos de la senda de la conducta racional-egoísta. No estaríamos más que ante una variante particular de la misma, aquélla en que asumimos como propias las preferencias de otros individuos y tratamos de maximizar su utilidad. En este sentido, la maximización de la utilidad de los otros no es más que un medio para maximizar la nuestra. Así es como se suele plantear la conducta altruista en el marco de la teoría estándar de la racionalidad. El caso planteado no diferiría en su naturaleza de la felicidad que sentimos al hacer feliz a alguien haciéndole un regalo. Este fenómeno, típicamente humano y que entronca directamente con nuestra capacidad de empatía, puede englobarse claramente en lo que intuitivamente entendemos como virtud y como tal se incluye en esta caracterización. Aún es posible y necesario no obstante, dar un paso más y abandonar completamente la conducta racional-egoísta. Pese a que los autores no abordan explícitamente esta cuestión, la solidaridad debe incluir también la noción de compromiso si es que ha de sernos útil para caracterizar correctamente el concepto de virtud cívica. Si, continuando con el ejemplo anterior, el conocimiento de que se tortura no nos enferma pero nos movilizamos contra la misma por sentido del deber, estaremos ante un caso de compromiso.

Motivaciones solidarias de este tipo deben ser consideradas como constitutivas de la virtud. Sin embargo, que es aún posible dar un paso más en la caracterización de las motivaciones virtuosas, y por tanto, que éstas pueden incluir también el altruismo perfecto.

Por altruismo perfecto se entiende la creencia de que todos los seres humanos somos iguales y el deseo de obrar en consecuencia (Kolm 1983). Debe quedar claro que no consiste en sacrificar de forma incondicional el propio bienestar en aras del bienestar de los demás. Esta idea escapa a lo que aquí se concibe como virtud y, pese a que pueden encontrarse multitud de ejemplos de comportamientos admirables en este sentido, también se abre la puerta, como tendrá oportunidad de verse más adelante, a derivas muy peligrosas. Se trataría más bien de actuar motivado por la consecución de la justicia práctica.

\section{LOS PELIGROS DEL ALTRUISMO}

Existe aún una cuestión importante acerca de lo que puede considerarse o no como virtud cívica, que se ha insinuado más arriba. Antes se ha apuntado que podemos encontrar motivaciones viciosas que den lugar a resultados positivos y motivaciones morales con consecuencias desastrosas. Este segundo hecho acaba de volver a ser insinuado hace un momento cuando se ha sostenido que el sacrificio incondicional del 
propio interés en aras del bien común puede acabar teniendo consecuencias negativas. Se ha venido sosteniendo que las motivaciones virtuosas tienen una relación instrumental con las acciones correctas. Esto significa que el vínculo es empírico, no analítico, la experiencia práctica nos dice que cuando actuamos motivados de forma virtuosa solemos llevar a cabo acciones correctas y, a la inversa, cuando actuamos siguiendo motivaciones viciosas, en ausencia de medidas institucionales de control, solemos llevar a cabo actos incorrectos, pero esto no tiene por qué ser así en todos los casos.

El primer caso se argumentará a partir de un ejemplo real: hace ya algunos años tuve la oportunidad de ver en televisión un acto promocional del partido benéfico de fútbol que se celebra cada año con objeto de recaudar fondos para la Fundación de Ayuda contra la Drogadicción (FAD). Entre los impulsores de esta iniciativa se encuentran, entre otros Johann Cruyff, el juez Baltasar Garzón y los periodistas Luis del Olmo y José María García. El partido se disputaba por aquel entonces un año en Barcelona y otro en Madrid. Aquélla era, si no me falla la memoria, la segunda edición. La primera se había disputado en Barcelona con un rotundo éxito de asistencia de público. El caso es que en un momento del acto, José María García comenzó a dirigirse a los madrileños más o menos en estos términos: "Ya sé que no está bien utilizar este tipo de argumentos y que va contra el código deontológico de mi profesión pero..., por una vez, permitidme que me dirija a los madrileños para preguntarles si vamos a dejar que los catalanes... que, entre nosotros..., ya sabemos la fama de tacaños que tienen..., pasen por ser más generosos, más solidarios y más comprometidos que nosotros". Finalmente, los catalanes acabaron siendo, al menos en aquella ocasión, más virtuosos que los madrileños pero, sea como sea, está claro que lo que pretendía García era conseguir que los madrileños hiciesen lo correcto aunque fuese por los motivos incorrectos. Podríamos encontrar ejemplos muchísimo más serios que éste, pero el que he escogido resulta muy ilustrativo.

Una tema mucho más complejo es el inverso, actos morales que acaban teniendo consecuencias nefastas. Tal y como señala Noguera:

[...] pueden existir "santos" inmorales, por no hablar de "santos" ignorantes, irresponsables o estúpidos: la "virtud altruista" no siempre es garantía de buenos actos, y los "santos" morales pueden llevarnos al desastre moral a nivel social, sobre todo si se enfrentan con "santos" de otras religiones contrarias a la suya. (Noguera 2003: 18).

Siendo esto así, debemos ser tremendamente cautelosos a la hora de determinar qué grado de moralidad y en particular, qué grado de altruismo exigimos a la virtud. Efectivamente, en ocasiones se da por supuesto que las motivaciones altruistas son positivas por naturaleza pero ésta es una tesis que dista mucho de ser obvia. En un mundo en el que el terrorismo internacional constituye uno de los principales desafíos para las sociedades democráticas, parece evidente que determinados tipos de motivaciones morales (en particular el altruismo entendido como el sacrificio incondicional del interés individual en aras de algún bien colectivo) resultan extremadamente peligrosos. Lo que se pretende argumentar aquí es que debemos ser muy cautelosos respecto del 
grado de altruismo que exigimos a la virtud cívica. Permítase realizar una sugerencia a modo de ejemplo. Podríamos plausiblemente tratar de argumentar que ETA empezó a perder capacidad de reclutar nuevos militantes a medida que la juventud vasca, del mismo modo que ha sucedido en la mayoría de democracias occidentales, se fue despolitizando progresivamente. Nótese que lo que se sugiere no es que la juventud fue abandonando los postulados abertzales para abrazar tesis democráticas y de tolerancia $y$, finalmente, oponerse a la violencia. Lo que se sugiere es que disminuyó el grado de politización de la juventud mientras que aumentó el interés por la vida privada.

El sacrificio incondicional del propio interés, en aras de los intereses de los demás o de una determinada concepción del bien común, puede producir consecuencias negativas tanto como positivas, y por ello se lo excluye explícitamente de la caracterización de la virtud cívica que se está tratando de esbozar en estas páginas. Así pues, en modo alguno se puede considerar que los jóvenes que queman autobuses sean virtuosos, aunque sí que son altruistas y actúan guiados por motivaciones morales, por muy incorrectas que puedan ser. Con este argumento no se incurre en la falacia denunciada por Goodin (1992). Según él, una salida fácil y frecuente al problema de las motivaciones de carácter moral con consecuencias negativas pasa por argumentar que eso no son realmente conductas morales o lo son sólo parcialmente. Por esta vía se acaba armando una tesis puramente definicional, en ocasiones incluso tautológica, acerca de lo que es 0 no una motivación moral. De este modo acabamos abocados irremediablemente al problema de no poder decidir si una motivación es o no moral hasta que no comprobemos los resultados de la acción que genera. Paradójicamente, esto es justo lo contrario de lo que pretendíamos y produce, además, insuperables dificultades de cara al diseño de instituciones moralizantes.

Por el contrario, aquí, como hace Goodin, se acepta que el vínculo entre motivaciones y acciones correctas es empírico, no constitutivo. De este modo, en primer lugar, se asume que motivaciones villanas pueden dar lugar a conductas correctas. En segundo lugar, se asume que motivaciones morales (como el altruismo incondicional) pueden dar lugar a conductas incorrectas. Pero en tercer lugar, y éste puede ser el aspecto más controvertido de la argumentación en este punto, no se acepta que las motivaciones virtuosas puedan dar lugar a acciones incorrectas ${ }^{9}$. Esto es así debido a que se ha limitado mucho la carga moral del concepto de virtud cívica. La caracterización no es excesiva. Ninguno de los principios defendidos conduce en modo alguno a la intolerancia, al contrario, se trataría, de hecho, de encontrar una forma de institucionalización de una regla de tolerancia ${ }^{10}$.

\footnotetext{
${ }^{9} \mathrm{~A}$ no ser que sea debido a un error cognitivo, de ejecución de la acción o cosas por el estilo. Yo puedo ayudar a una anciana a cruzar la calle cuando creo que el semáforo de peatones está en verde sin percatarme de que se aproxima un autobús que, por mi culpa, acaba matando a la anciana. Pero no es éste el tipo de acciones que denominamos incorrectas en este contexto.

${ }^{10}$ Las conductas virtuosas, tal y como han sido definidas aquí, sí que pueden producir resultados inefi-
} 


\section{LA EXTENSIÓN SOCIAL DE LA VIRTUD CÍVICA}

Hasta aquí han tratado de definirse algunas de las características de la virtud cívica. Se ha sostenido que, por virtud debe entenderse un tipo de motivación, y no determinados rasgos estables de carácter 0 determinadas conductas. Se ha explorado también el tipo de motivaciones que podrían ser denominadas virtuosas y se ha determinado que éstas podrían consistir en la motivación para la cooperación y para sancionar a los que no cooperan, en altruismo y en solidaridad. Llegados a este punto, cabe preguntarse empero, en qué debería consistir la extensión social de la virtud. Responder a dicha pregunta resulta crucial de cara a poder plantearse diseños institucionales concretos que puedan promover la virtud cívica. Philip Pettit entiende que una comunidad cívica es aquélla en la que los ciudadanos actúan generalmente guiados por un cuerpo de normas sociales públicamente orientadas (Pettit 1999). De este modo, la extensión social de la virtud consistiría en hacer emerger un cuerpo de normas sociales de este tipo.

Al igual que sucede con la virtud, no existe hoy todavía pleno acuerdo acerca de qué debemos entender con el concepto de "norma social". No obstante, la publicación en 2006 del trabajo de C. Bicchieri The grammar of the society ha sentado un antes y un después en el debate. Bicchieri traza una distinción entre normas morales y sociales y sostiene que los agentes albergan una preferencia de tipo condicional para cumplir con éstas últimas.

Las normas morales, a diferencia de las sociales, son incondicionales. Seguimos las normas morales independientemente de lo que hagan o piensen otros. Las seguimos porque contamos con buenas e independientes razones para hacerlo. Las expectativas o las preferencias de los demás no proporcionan una buena razón para seguir una norma moral. Seguimos normas morales porque consideramos que son buenas en sí mismas, la razón para obedecer una norma de este tipo, por tanto, reside en el contenido de la norma misma.

Las normas sociales en cambio son de tipo condicional. Existen cuatro condiciones que son individualmente necesarias y conjuntamente suficientes para -y por tanto, constitutivas de - la existencia de una norma social. Éstas son: la contingencia, las expectativas empíricas, las expectativas normativas y las preferencias condicionales. Según la autora,

Condiciones para la existencia de una norma social

Sea $R$ una regla de comportamiento en situaciones del tipo $S$, donde $S$ puede ser

cientes en el nivel agregado. Como en el famoso ejemplo de Elster (2002), si todos los invitados a una cena a la que acuden 10 personas insisten en ayudar a recoger al terminar, seguramente tardarán más en acabar que si 8 se hubiesen sentado y 2 se hubiesen ocupado de realizar todo el trabajo. Nuevamente, esto habla a favor de la articulación del diseño institucional y de la virtud cívica como óptimo social. 
representado como un juego de motivos mixtos. Decimos que $R$ es una norma social en una población $P$ si existe un subconjunto suficientemente grande $P_{c f} \subseteq P$ de modo que, para cada individuo $i \in P_{c f}$

Contingencia: i sabe que la regla existe y que se aplica a situaciones del tipo $S$; Preferencia Condicional: i prefiere ajustarse a $R$ en situaciones del tipo $S$ a condición de que:

(a) Expectativas Empíricas: $i$ cree que un subconjunto suficientemente grande de $P$ se ajusta a $R$ en situaciones del tipo $S$;

y, o bien

(b) Expectativas Normativas: i cree que un subconjunto suficientemente grande de $P$ espera que $i$ se ajuste a $R$ en situaciones del tipo $S$;

o bien

(b') Expectativas Normativas con Sanciones: i cree que un subconjunto suficientemente grande de $P$ espera que $i$ se ajuste a $R$ en situaciones del tipo $S$, prefiere que $i$ se ajuste, y podría sancionar la conducta (Bicchieri 2006: 11).

La caracterización de Bicchieri constituye una reconstrucción racional del cumplimiento de normas sociales en términos de creencias y preferencias. Dicha reconstrucción no pretende ser un reflejo fiel de los procesos mentales reales a través de los cuales los individuos siguen las normas, se trata más bien de ofrecer una explicación de las normas sociales que permita, por una parte, dilucidar un sentido preciso en el que puede considerarse que un agente que sigue una norma actúa de forma racional y, por otra parte, generar modelos explicativos y predictivos aplicables a situaciones concretas.

Nótese que la caracterización ofrecida supone reconocer que en una determinada sociedad la virtud cívica puede hallarse socialmente extendida, en el sentido de que puede existir un cuerpo de normas sociales públicamente orientado bien establecido, y, sin embargo, puede que los ciudadanos no siempre se comporten del modo en que la virtud les requeriría. Este hecho puede deberse a varios factores. Puede ser, en primer lugar, que existan numerosas situaciones en las que sería deseable para el bien común que los ciudadanos actuasen siguiendo las normas públicamente orientadas socialmente existentes, pero que, sin embargo, esos mismos ciudadanos no reconozcan esas situaciones como del tipo en que se aplica una norma social.

En un ejercicio de lo que podríamos denominar como folk psychology ingenua, los seres humanos solemos concebirnos a nosotros mismos y a los demás como guiados por motivaciones que tienen su origen en disposiciones y rasgos de carácter más 0 menos estables en el tiempo (Bicchieri 2008; Elster 2007). En este sentido, decimos de alguien que es honesto cuando consideramos que tiene interiorizada una norma de honestidad que guía su conducta habitualmente. En un extremo, siguiendo la postura de los clásicos al respecto, podríamos suponer que todas las virtudes van juntas de modo que quien alberga una las alberga todas y constituye una persona moralmente buena, a la inversa, lo mismo sucedería con los vicios (Elster 2007). 
Esta concepción de la conducta y la motivación humanas ha sido dominante durante siglos, no ya en la psicología popular sino en la filosofía y en las ciencias sociales. No obstante, hace tiempo que desde la psicología cognitiva y otras ciencias aledañas se viene aportando evidencia empírica que parece mostrar que se trata de una concepción errónea en una importante medida, víctima de lo que ha venido a denominarse como el fundamental attribution error (Bicchieri 2006; Elster 2007).

Ser honesto es una característica personal pero, en un aspecto importante, es también una característica local o situation-specific en el sentido de que en muchas ocasiones el factor con mayor poder explicativo de la conducta es la situación y no la persona (Elster 2007). Veámoslo con un ejemplo, en un experimento con estudiantes de Teología, a unos se les pidió que discutiesen durante un rato sobre la Parábola del buen samaritano y a otros sobre un tema sin trascendencia moral. Terminada la discusión se les pidió que se dirigiesen a otro lugar. A unos se les dijo que los estaban esperando y que debían darse prisa, al resto no se le dio ninguna instrucción especial. En el trayecto hacia el otro lugar encontraron a un indigente pidiendo limosna (uno de los experimentadores). Sólo el $10 \%$ de los sujetos a los que se les indicó que debían darse prisa se detuvo a ayudar al indigente, en el otro grupo más de la mitad de los sujetos se detuvo. Ni el tema sobre el que habían estado discutiendo ni ningún otro factor similar controlado por los experimentadores pareció tener incidencia alguna en el resultado, por el contrario, parece que fue el hecho de encontrarse en una situación relajada o el tener prisa el factor con mayor poder explicativo de la conducta.

De manera general, tal y como explicita Bicchieri, los diferentes contextos en los que nos encontramos presentan unas características que resultan prominentes para nosotros, se trata de señales que captan nuestra atención (attention cues). A través de toda una serie de procesos que funcionan por debajo de nuestra conciencia, los seres humanos interpretamos esas señales y categorizamos la situación como de un tipo u otro. Dependiendo de las señales que percibamos y de cómo las interpretemos podemos categorizar una situación como una del tipo en la que opera una norma de equidad o en la que lo pertinente es perseguir el propio interés, etc. Una vez que hemos categorizado una situación se activan nuestros schemata. Los schemata son estructuras cognitivas que representan el conocimiento almacenado sobre personas, eventos, roles, etc. Los schemata relacionados con las normas se denominan scripts, a saber, schematas referidos a cómo es apropiado comportarse en un determinado contexto. Las normas sociales están enraizadas dentro de scripts. Cuando una situación se identifica como de un cierto tipo, se activan scripts con actores, roles, expectativas compartidas de lo que se espera que suceda, preferencias, etc.

El diseño institucional constituye una herramienta poderosísima para definir las situaciones, los contextos, de un modo u otro y alterar así la motivación de los agentes. Una ley bien diseñada, por ejemplo, será aquélla que, entre otras cosas, induzca a los agentes a categorizar las situaciones a las que se aplica como de un tipo tal que resulta pertinente cumplir con dicha ley y cooperar así en la promoción del bien público. En el otro extremo, una ley mal diseñada será aquélla que desmotive a un agente que hasta 
ese momento estaba cumpliendo por voluntad propia. Una vez más, por tanto, encontramos elementos para argumentar que la correcta articulación entre la virtud cívica y el diseño institucional puede constituir un óptimo social.

En segundo lugar, la virtud cívica puede fracasar en el cometido de promover la conducta correcta incluso en aquellas situaciones en las que se encuentran interactuando individuos que identifican dicha situación como una del tipo en la que se les requiere que actúen correctamente y se encuentran además motivados para hacerlo.

Aunque generalmente es de esperar que la existencia de una norma social dé lugar a una regularidad de conducta, esto no tiene por qué ser así siempre. Una norma social existe si el conjunto de individuos que la alberga, el conjunto de seguidores condicionales (Pcf) dentro de la población $(P)$ es suficientemente numeroso. Pero la norma social sólo se cumplirá de forma efectiva si el conjunto de individuos que efectivamente la siguen (Pf) es, nuevamente, suficientemente numeroso (Bicchieri 2008: 12). Existen algunas situaciones por tanto en las que es posible que las condiciones enumeradas en la definición de la norma se cumplan, es decir, que la norma exista, pero, sin embargo, ésta no se cumpla, a saber, no se dé regularidad de conducta alguna.

En primer lugar, podemos hallarnos ante un caso de ignorancia pluralística (Miller y Prentice 1994) combinado con una norma el cumplimiento de la cual no puede ser observado directamente. Por ejemplo, imaginemos una comunidad en la que existe una norma en contra de las relaciones sexuales prematrimoniales ${ }^{11}$. La norma existe ya que se cumple que los individuos saben que existe $R$ ("abstenerse de mantener relaciones sexuales") y que se aplica a $S$ (relaciones entre individuos solteros). En una situación así, el individuo i cree que los demás están cumpliendo, que esperan que él haga lo mismo y que van a sancionarlo duramente si lo descubren incumpliendo la norma. Dadas todas estas condiciones, el individuo $i$ (y todos los demás) prefiere cumplir. Pero, evidentemente, es muy difícil determinar si la conducta en cuestión se cumple o no. De hecho, en este tipo de normas que regulan la conducta privada, lo que se observa son las consecuencias del cumplimiento, no el cumplimiento en sí. En este caso observamos la ausencia de embarazos entre las mujeres solteras, de lo que es posible inferir, erróneamente o no, que la norma se cumple. No obstante, en éste y en otros muchos casos es posible que observemos las consecuencias del cumplimiento sin que éste se produzca realmente. En este ejemplo puede que las parejas solteras utilicen métodos anticonceptivos de algún tipo. De este modo, finalmente puede que prácticamente nadie cumpla con la norma pero que ésta continúe existiendo y siendo efectiva. Pese a que nadie cumple, puede que todos piensen que los demás cumplen y que esperan que ellos lo hagan. Es más, si alguien es descubierto puede que sea incluso más duramente sancionado por aquellos que no siguen la norma que por aquellos que sí que lo hacen.

En segundo lugar, una norma puede existir y no ser seguida debido a que los seguidores condicionales de la misma (Pcf) se ven siempre abocados a un juego bayesiano

${ }^{11}$ Éste no es un ejemplo, obviamente, de norma públicamente orientada. 
que no tiene por que concluir necesariamente siempre con el cumplimiento. Veamos esto con mayor detalle:

Según Bicchieri, una norma da solución a un mixed-motive game. Un mixed-motive game es un tipo de juego de estrategia en el que los intereses de los jugadores resultan parcialmente divergentes pero también parcialmente coincidentes. Que las normas sociales den solución a un juego de este estilo significa que transforman un dilema original de estas características en un juego de coordinación y ayuda a los jugadores a seleccionar el equilibrio óptimo en este último.

Imaginemos que los agentes se encuentran en una situación $S$ que puede ser modelizada como un problema de bienes públicos, más concretamente como un dilema del prisionero, y que no existe ninguna norma social. En una situación así, el orden de preferencias de cada agente será el que se muestra en la Figura 1.

Figura 1.

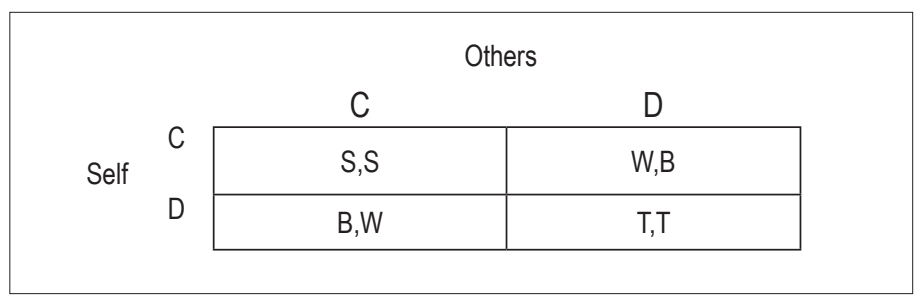

Fuente: Bicchieri (2006: 26).

Las letras que se encuentran en el interior de la tabla corresponden al inglés: B: best, S: second best, T: thirt best y W: worst. Vemos como el orden de preferencias corresponde con el del mencionado dilema del prisionero.

Si una norma que prescribe la mutua cooperación entra en funcionamiento y, por tanto, se cumplen las condiciones anteriores, las preferencias de los agentes se transformarán de tal modo que el mixed-motive game previo se transformará en un juego de coordinación de este estilo.

Figura 2.

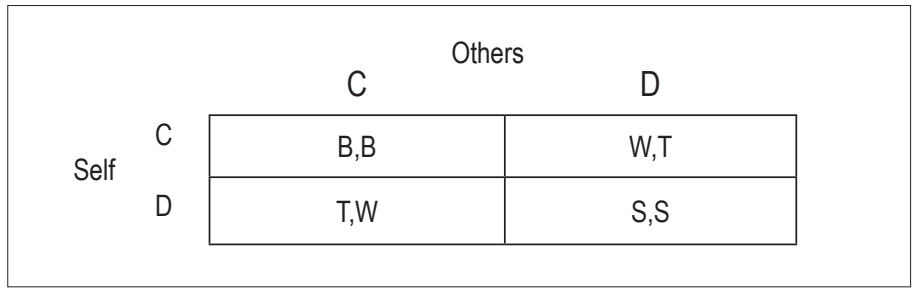

Fuente: Bicchieri (2006: 26). 
En este nuevo juego podemos observar la existencia de dos equilibrios de Nash con estrategias puras (C,C y D,D), con la característica de que el primero de ellos es óptimo de Pareto respecto del segundo, que es subóptimo. Ahora todos los agentes tendrán interés en coordinarse en torno al equilibrio óptimo pero puede que no lo logren por un problema de confianza.

Es importante recordar en este punto que para que una norma exista no es necesario que todos y cada uno de los individuos en $P$ se encuentre motivado por la misma. Siempre habrá personas que no se hallen motivadas para cumplir y que, por tanto, continúen jugando el dilema del prisionero original. Veamos que puede llegar a implicar lo anterior a partir de un ejemplo con sólo dos jugadores. Siempre que un Pcf se encuentre frente a un agente desconocido sobre el que no tiene información, deberá contemplar la posibilidad de hallarse ante un free-rider que tratará de explotarlo. Por tanto, los Pcf se ven habitualmente enfrentados a juegos bayesianos, a situaciones de riesgo, en las que sólo pueden saber que, o bien están jugando un mixed-motive game con probabilidad $p 0$ bien están jugando un juego de coordinación con probabilidad 1-p. En estas circunstancias, resulta plausible suponer que en ocasiones dos Pcf se encuentren en una situación $S$ y que, pese a hallarse motivados para cumplir la norma existente, ninguno de los dos lo haga por un problema de confianza.

Una vez más, un buen diseño institucional puede favorecer que los individuos puedan desplegar su virtud y alcanzar el equilibrio cooperativo merced a través de introducir en el sistema la confianza que los virtuosos necesitan para cooperar sin temor a verse explotados por potenciales free-riders.

Por otra parte, cuando los ciudadanos virtuosos actúen siguiendo normas morales no se verán enfrentados a este problema ya que dichas normas, como vimos, son de tipo incondicional. En este sentido, del hecho de que la extensión social de la virtud tanto pueda consistir en hacer emerger normas morales como sociales se deriva, una vez más, que la virtud cívica puede ser tanto condicional como incondicional.

Otro debate de crucial importancia en torno a la virtud cívica se refiere al hecho de si ésta es o no una motivación de tipo consecuencialista. Como en el caso anterior, la respuesta que se ofrecerá en estas páginas a dicha pregunta será que puede adoptar ambas formas. Por una parte, ni las normas morales ni las sociales que se siguen independientemente de la existencia de sanciones son consecuencialistas. En cambio, las normas sociales que se siguen merced a la existencia de sanciones sí que lo son. De este modo, la virtud cívica tanto puede ser consecuencialista como no consecuencialista.

Que las normas morales no son consecuencialistas es una conclusión lógica de su naturaleza. Las normas morales deben cumplirse siempre, independientemente de lo que hagan los demás o de las consecuencias que tal conducta pueda llegar a tener.

Las normas sociales que se siguen independientemente de la existencia de sanciones son también de tipo no-consecuencialista. El no-consecuencialismo es lo que distingue a una simple preferencia por un determinado producto de la acción de una preferencia condicional por seguir una norma (Bicchieri 2006: 57-58). Recogiendo el 
mismo ejemplo puesto por la autora, no es lo mismo tener una preferencia por la equidad que tener una preferencia condicional para seguir una norma de equidad. La primera es una motivación orientada a futuro, lo que interesa es, estrictamente, el producto de la acción. La segunda es una preferencia orientada al proceso, lo que preferimos (condicionalmente) es actuar de forma justa, independientemente de las consecuencias.

Finalmente, las normas sociales en el caso b' de Bicchieri (Expectativas Normativas con Sanciones), aquellas que se sostienen únicamente por las sanciones aplicadas a los violadores, son de naturaleza claramente consecuencialista. El agente cumple con lo que la norma prescribe o proscribe únicamente por los beneficios que espera obtener y/o las sanciones que espera evitar como resultado de su conducta.

\section{CONCLUSIONES}

A lo largo de estas páginas se ha intentado ofrecer algunas líneas básicas de lo que debería ser una definición sociológica del concepto de virtud cívica. Se ha sostenido que debemos entender la virtud cívica como la motivación para actuar de forma públicamente orientada.

En este sentido, se ha argumentado que la virtud cívica es un tipo de motivación y no un tipo de disposición o de conducta. Posteriormente, se ha sostenido que la motivación virtuosa puede consistir en motivaciones para la cooperación y para sancionar a los que no cooperen, así como en motivaciones de tipo solidario y altruista. No obstante, no todas las motivaciones morales y, en particular, no todas las motivaciones altruistas pueden ser calificadas de virtuosas.

En otro orden de cosas, se ha sostenido también que la extensión social de la virtud consistirá en la promoción de un cuerpo de normas morales y sociales públicamente orientadas. Concebir de este modo la extensión social de la virtud cívica permite reconocer que pueden existir situaciones en las que, aún existiendo virtud cívica, los agentes no actúan de forma correcta. Este hecho, junto con otros a los que se ha ido haciendo referencia a lo largo del trabajo, aportan razones a favor de concebir la correcta articulación entre virtud cívica y diseño institucional como un óptimo social.

La concepción de la virtud cívica defendida en estas páginas es transversal a dos importantes debates tradicionales: la virtud puede adoptar la forma de motivaciones condicionales o incondicionales, así como consecuencialistas o no consecuencialistas.

\section{REFERENCIAS BiBLIOGRÁFICAS}

Aristóteles, 1981. Ética a Nicomaco. Madrid: Centro de Estudios Constitucionales.

Arnsperger, C. y Yanis Varoufakis. 2003. "Toward a theory of solidarity." Erkenntnis 59: 157-188. 
Bertomeu, M. J. y Antoni Domènech. 2005. "El republicanismo y la crisis del rawlsismo metodológico (Nota sobre método y sustancia normativa en el debate republicano)." Isegoría 33: 51-75.

Bicchieri, C. 2006. The Grammar of Society. The Nature and Dynamics of Social Norms. Cambridge: Cambridge University Press.

Bowles, S. y Herbert Gintis. 2001. "¿Ha pasado de moda la igualdad? El homo reciprocicans y el futuro de las políticas igualitarias." Pp. 171-194 en Razones para el Socialismo, compilado por R. Gargarella y F. Ovejero. Barcelona: Paidós.

Brennan, G. and Alan P. Hamlin. 1995. "Economizing on virtue." Constitutional Political Economy 6: $35-60$.

Cicerón. 1982. Sobre la República. Sobre las leyes. Madrid: Tecnos.

Cicerón. 1989. Sobre los deberes. Madrid: Alianza Editorial.

Elster, J. 2002. Alquimias de la mente. La racionalidad y las emociones. Barcelona: Paidós, El Roure.

Elster. 2007. Explaining Social Behavior. More nuts and bolts for the social sciences. Cambridge: Cambridge University Press.

Frölich, N. y Joe A. Oppenheimer 1992. Choosing justice. Berkeley and Los Angeles: University of California Press.

Goodin, R. 1992. Motivating political morality. Massachussets: Blackwell Publishers.

Herreros, F. 2002. ¿Por qué confiar? El problema de la creación del capital social. Madrid: CEACS Instituto Juan March.

Hurka, T. 2006. "Virtuous act, virtuous dispositions." Análisis 66.1: 69-76.

Johnson, R. N. 2003. "Virtue and right." Ethics 113: 810-834.

Kolm, S. 1983. "Altruism and efficiency." Ethics: 18-66.

Miller, D. T. and Deborah A. Prentice. 1994. "Collective errors and errors about the collective." Personality and Social Psychology Bulletin 20: 541-550.

Noguera, J. A. 2003. "Rawlsianos, marxistas y santos: sobre el socialismo igualitarista de G.A. Cohen." Ponencia presentada en el IV Congrés Català de Sociologia, 5 y 6 de abril. Reus.

Ovejero, F., José Luis Martí y Roberto Gargarella. 2004. "Introducción: La alternativa republicana". Pp. 1-74 en Nuevas ideas republicanas. Autogobierno y libertad, compilado por F. Ovejero, J. L. Martí y R. Gargarella. Barcelona: Paidós.

Pettit, P. 1999. Republicanismo. Una teoría sobre la libertad y el gobierno. Barcelona: Paidós.

Putnam, R. 2000. Per a fer que la democràcia funcioni. La importància del capital social. Barcelona: Proa. 
Sen, A. 1986. "Los tontos racionales: una crítica de los fundamentos conductistas de la teoría económica." Pp. 172-217 en Filosofía y Teoría Económica, compilado por F. Hahn y M. Hollis. México: Fondo de Cultura Económica.

Tocqueville, A. de. 1969. La democracia en América. Vol. 2. Madrid: Alianza Editorial.

JORDI TENA es Doctor en Sociología por la Universitat Autònoma de Barcelona y miembro del Grupo de Sociología Analítica y Diseño Institucional (GSADI). Su principal área de interés es la teoría social. En este ámbito investiga en el terreno de la teoría social analítica, el diseño institucional y la filosofía política contemporánea. Entre sus publicaciones cabe destacar "Exploring Mechanisms of Institutional Design which Promote Compliance", Papers 2010; "La Virtud Cívica en el Liberalismo Político Igualitarista", Isegoría, 2010; "Estrategias de Diseño Institucional, Cumplimiento y Virtud Cívica", Revista de Ciencia Política 2009 y "Monitoring and evaluating participation in national forest programmes. The Catalan case", Swiss Forestry Journal, 2006 (con Glòria Domínguez).

\section{RECIBIDO: $\quad 04 / 11 / 2007$}

ACEPTADO: 10/11/2008 